\title{
Sacarose e período de cultivo in vitro na aclimatização ex vitro de ginseng brasileiro (Pfaffia glomerata Spreng. Pedersen)
}

\author{
Sucrose and duration of in vitro growth on ex vitro acclimatization of Brazilian ginseng \\ (Pfaffia glomerata Spreng. Pedersen)
}

Etiane Caldeira Skrebsky ${ }^{1}$ Fernando Teixeira Nicoloso ${ }^{2}$ Gregori da Encarnação Ferrão ${ }^{3}$

RESUMO

Pfaffia glomerata (Spreng.) Pedersen é uma planta extensivamente usada na medicina popular em decorrência de possuir propriedades fitoterápicas. Devido à sua baixa capacidade fotossintética, as plantas cultivadas in vitro requerem uma fonte extra de carboidratos para suprir suas necessidades metabólicas. O tempo de cultivo in vitro influencia as taxas de crescimento das raízes e da parte aérea de $\boldsymbol{P}$. glomerata. Este trabalho teve como objetivos avaliar os efeitos da sacarose e do período de cultivo in vitro na aclimatização ex vitro de plântulas de $\boldsymbol{P}$. glomerata. Os tratamentos consistiram de uma combinação bifatorial (5x2) entre cinco concentrações de sacarose $\left(15,30,45,60\right.$ e $\left.75 \mathrm{~g} \mathrm{~L}^{-1}\right) e$ dois períodos de cultivo in vitro ( 25 e 32 dias após a inoculação). No cultivo in vitro, a parcela experimental consistiu de um tubo de ensaio contendo $10 \mathrm{~mL}$ de meio MS e um segmento nodal, obtidos de plântulas mantidas in vitro, de $1,0 \mathrm{~cm}$ de comprimento $e$ sem folhas. $O$ procedimento de aclimatização consistiu de quatro fases sucessivas de cultivo ex vitro: (i) abertura dos tubos de ensaio e exposição das plântulas ao ambiente de câmara climatizada por três dias; (ii) transplantio para substrato Plantmax e cultivo em condições de câmara climatizada por 21 dias; (iii) transferência das mudas para ambiente natural parcialmente sombreado, com duração de 24 dias; $e$ (iv) transplantio para solo em condições de cultivo a campo. O maior crescimento das plantas obtido pelo aumento da disponibilidade de sacarose (concentrações entre 45 e $\left.60 \mathrm{~g} \mathrm{~L}^{-1}\right)$ no cultivo in vitro contribuiu para a aclimatização. Independente do período de retirada das plantas do cultivo in vitro, as mudas obtiveram adequada aclimatização. O procedimento de aclimatização foi $100 \%$ eficiente na produção de mudas de $\boldsymbol{P}$. glomerata.

Palavras-chave: micropropagação, carboidrato, produção de mudas, autotrofismo, heterotrofismo.

\section{ABSTRACT}

Pfaffia glomerata (Spreng.) Pedersen is an extensively used plant in popular medicine due to its phytotherapic characteristics. Due to low photosynthetic capacity of plants cultivated in vitro, an extra source of carbohydrates is required to supply their metabolic demands. The growth rate of roots and

\begin{abstract}
shoots of $\boldsymbol{P}$. glomerata are different during the in vitro cultivation. The objectives of this study were to evaluate the effect of sucrose levels and the duration of in vitro growth on ex vitro acclimatization of $\boldsymbol{P}$. glomerata seedlings. Treatments consisted of a bifactorial combination (5x2) of five sucrose levels $\left(15,30,45,60\right.$ and $\left.75 \mathrm{~g} \mathrm{~L}^{-1}\right)$ and two periods of in vitro cultivation (25 and 32 days after inoculation). In the in vitro cultivation, the experimental unit consisted of a test tube containing $10 \mathrm{~mL}$ of MS medium and a nodal segment, from in vitro cultivated plants, of $1,0 \mathrm{~cm}$ in length without leaves. The acclimatization scheme consisted of ex vitro cultivation by four successive phases: (i) opening of the test tube and subsequent cultivation in growth room for three days; (ii) seedlings subcultivation to Plantmax substrate and cultivation in growth room for 21 days; (iii) seedlings transfer to partially shady natural environment for 24 days; and (iv) seedling subcultivation to soil under field condition. The greatest plant growth by increasing the sucrose availability (levels among 45 and $60 \mathrm{~g} \mathrm{~L}^{-1}$ ) during the in vitro growth contributed to acclimatization. Regardless of duration of the in vitro growth, the seedlings obtained and efficient acclimatization. The acclimatization procedure was $100 \%$ efficient on seedling production of $\boldsymbol{P}$. glomerata.
\end{abstract}

Key words: micropropagation, carbohydrate, seedling production, autotrophy, heterotrophy.

\section{INTRODUÇÃO}

O gênero Pfaffia, particularmente a espécie Pfaffia glomerata, estende-se por toda a América do Sul desde a Guiana até a Bolívia e Argentina, e no Brasil ocorre em todas as regiões (SMITH \& DOWNS, 1972). A Pfaffia glomerata, uma das espécies conhecidas como ginseng brasileiro, é considerada medicinal por possuir características rejuvenescedoras, revitalizantes, inibidoras do crescimento de células cancerígenas, ativadoras da circulação do sangue, es-

\footnotetext{
${ }^{1}$ Engenheiro Agrônomo, Doutoranda pelo Programa de Pós-graduação em Agronomia, Universidade Federal de Santa Maria (UFSM).

${ }^{2}$ Engenheiro Agrônomo, PhD, Professor Adjunto, Departamento de Biologia, Centro de Ciências Naturais e Exatas, UFSM, Campus Universitário, Camobi, 97105-900, Santa Maria, RS. E-mail: nicoloso@ base.ufsm.br. Autor para correspondência.

${ }^{3}$ Engenheiro Agrônomo, UFSM.
} 
timulantes das funções sexuais, antidiabéticas, combatente de estresses e enfermidades como inflamações e reumatismo (MONTANARI JÚNIOR., 2002).

Devido a propagação vegetativa da $\boldsymbol{P}$. glomerata via estaquia ser fisiologicamente viável, porém tecnicamente de baixo rendimento (NICOLOSO et al., 1999; NICOLOSO et al., 2001a), NICOLOSO et al. (2001b) desenvolveram um protocolo para a micropropagação desta espécie onde, a partir de um único segmento nodal, foi possível obter 15.000 plântulas dentro de um período de seis meses.

As células, tecidos e plântulas cultivadas in vitro não encontram condições adequadas de iluminação e concentração de $\mathrm{CO}_{2}$ e, às vezes, não apresentam teores de clorofila suficientes para realizar a fotossíntese que sustenta o crescimento (DALTON \& STREET, 1977; SOLÍS et al., 1989; GRO et al., 1993). Portanto, devido à baixa capacidade fotossintética das plantas cultivadas in vitro, essas requerem a adição de carboidratos para suprir suas necessidades metabólicas, quer participando na geração de energia ou como fonte de esqueletos carbônicos para vários processos biossintéticos implicados na diferenciação e crescimento celular (LEIFERT et al., 1995), sendo a sacarose o carboidrato mais apropriado para o cultivo da $\boldsymbol{P}$. glomerata (NICOLOSO et al., 2003).

As adaptações induzidas às plântulas cultivadas in vitro quando levadas ao ambiente ex vitro são denominadas comumente de aclimatização. Esse processo consiste de modificações morfoanatômico-fisiológicas necessárias às plantas para que possam sobreviver em um novo ambiente (CARVALHO et al., 1999). O aumento, a eliminação e/ou a redução da concentração de carboidratos no meio de cultivo pode ser determinante no sucesso da aclimatização (SOLAROVA et al., 1989; LIM et al., 1992; LEIFERT et al., 1995; CALVETE, 1998; LEITE et al., 2000).

As maiores taxas de crescimento de raízes e parte aérea de plântulas de $\boldsymbol{P}$. glomerata foram verificadas em momentos distintos do cultivo in vitro, sendo que até 15 dias após a inoculação dos explantes pouco incremento de biomassa da parte aérea foram observados (NICOLOSO et al., 2001b). Sabe-se que o sucesso no pegamento de mudas de várias espécies é dependente da razão entre a biomassa de raízes e da parte aérea. Portanto, o tempo de cultivo in vitro deve influenciar o pegamento ex vitro das mudas.

Este trabalho teve como objetivo avaliar o efeito da sacarose e do período de cultivo in vitro na aclimatização $\boldsymbol{e x}$ vitro de plântulas de $\boldsymbol{P}$. glomerata.

\section{MATERIAL E MÉTODOS}

Os tratamentos consistiram de uma combinação bifatorial $(5 \times 2)$ entre cinco concentrações de sacarose $\left(15,30,45,60\right.$ e $\left.75 \mathrm{~g} \mathrm{~L}^{-1}\right)$ e dois períodos de retirada das plântulas do cultivo in vitro ( 25 e 32 dias após a inoculação). No experimento de cultivo in vitro, o delineamento experimental foi o inteiramente casualizado com 60 repetições por tratamento. A parcela experimental consistiu de um tubo de ensaio ( $25 \mathrm{~mm}$ de diâmetro, $150 \mathrm{~mm}$ de altura e $147,26 \mathrm{~cm}^{3} \mathrm{de}$ volume interno) contendo $10 \mathrm{~mL}$ de meio $\mathrm{MS}$ (MURASHIGE \& SKOOG, 1962), solidificado com $0,6 \%$ de ágar e um segmento nodal de $1,0 \mathrm{~cm}$ de comprimento sem folhas. Os explantes foram obtidos de plântulas mantidas in vitro na ausência de fitoreguladores obtidas segundo o protocolo de NICOLOSO et al. (2001b). O pH do meio de cultivo foi ajustado para 5,8 antes da inclusão do ágar e da autoclavagem ( $\left.1 \mathrm{~atm}, 120^{\circ} \mathrm{C}, 15 \mathrm{~min}\right)$. O cultivo dos explantes foi realizado em câmara climatizada com temperatura de $25 \pm 1^{\circ} \mathrm{C}$ e fotoperíodo de $16 \mathrm{~h}$, sob intensidade luminosa de 1.500lux fornecida por lâmpadas fluorescentes branca-frias. Os recipientes de cultivo foram fechados com folha de papel alumínio e filme plástico PVC. Efetuaram-se avaliações do número de raízes aos $7,8,9,10,12$ e 15 dias após a inoculação (DAI), e aos 10, 25 e 32 DAI foram computadas a média da altura de brotações e média do número de segmentos nodais por brotação, bem como a matéria seca da parte aérea, de raízes e total das plântulas aos 25 e 32 DAI.

Plantas cultivadas in vitro até 25 e 32 DAI foram submetidas ao processo de aclimatização $\boldsymbol{e x}$ vitro, que consistiu de quatro etapas sucessivas. $\mathrm{Na}$ primeira etapa, com duração de três dias, as plântulas (30 por tratamento) ficaram expostas ao ambiente da câmara climatizada retirando-se o papel alumínio e o filme plástico PVC que fechavam a abertura dos tubos de ensaio. Na segunda etapa, as plântulas (15 por tratamento) foram transplantadas para recipientes plásticos contendo $250 \mathrm{~cm}^{3}$ de substrato comercial Plantmax Hortaliças e permaneceram sob condições de câmara climatizada por 21 dias. A umidade do substrato foi mantida entre 45 e $60 \%$ da capacidade de campo, através de irrigação com água destilada sempre por meio de aferições diárias por pesagem. Nessas duas primeiras etapas, as condições de luminosidade, temperatura e fotoperíodo foram as mesmas daquelas utilizadas no cultivo in vitro, e a umidade do ar foi de $60 \%$.

Na terceira etapa, as plantas (10 por tratamento) foram transferidas, por um período de 24 dias, 
para viveiro de mudas sob condições de sombrite (malha 50\%). A irrigação das plantas foi realizada por microaspersão a cada duas horas, seis vezes ao dia. Nas três primeiras etapas de aclimatização, utilizouse o delineamento experimental inteiramente casualizado, sendo a parcela experimental constituída de uma planta.

Na quarta etapa, as plantas ( 5 por tratamento) foram transferidas para condições de cultivo a campo. As plantas foram retiradas dos recipientes plásticos e transplantadas para o solo (Argissolo Vermelho distrófico arênico) previamente preparado em covas de $\pm 25 \mathrm{~cm}$ de profundidade, colocando-se $25 \mathrm{~g}$ de adubo NPK (5-20-20), num espaçamento de $1 \mathrm{~m}$ entre linhas e $0,60 \mathrm{~cm}$ entre plantas. A irrigação foi realizada diariamente por meio de regadores manuais, devido à intensa radiação solar observada durante os dois meses iniciais.

No final da segunda e terceira etapas de aclimatização, foram retiradas cinco amostras de plantas para a avaliação da matéria seca da parte aérea, de raízes e total das plântulas, bem como a sobrevivência das plantas no final das três últimas etapas. A análise dos dados foi realizada por regressão (fator concentração de sacarose) e por comparação de médias (fator época de retirada das plantas do cultivo in vitro) utilizando-se o software SOC/EMBRAPA - Campinas, SP, ao nível de 5\% de probabilidade de erro.

\section{RESULTADOS E DISCUSSÃO}

As primeiras raízes surgiram na base dos explantes aproximadamente aos 7 dias após a inoculação (DAI), logo após o surgimento das primeiras folhas. $\mathrm{O}$ maior número de raízes foi obtido entre as concentrações de 45 e $60 \mathrm{~g} \mathrm{~L}^{-1}$ aos 15 DAI (Figura 1a). Resultados relatados por NICOLOSO et al. (2001b) mostraram que plantas de $\boldsymbol{P}$. glomerata cultivadas in vitro em meio de cultura MS suplementado com $30 \mathrm{~g} \mathrm{~L}^{-1}$ de sacarose, dentro de um período de $35 \pm 5 \mathrm{DAI}$, apresentaram excelente desenvolvimento do sistema radicular, bem como da parte aérea.

Os níveis de sacarose no substrato de cultivo in vitro influenciam vários processos metabólicos nas culturas, apresentando efeito sobre o crescimento e diferenciação dos tecidos. GEORGE (1996) verificou que o aumento da concentração de sacarose, de modo geral, estimula o crescimento e a formação de raízes de algumas espécies. Já em outros trabalhos, na fase de enraizamento, a redução da concentração de sacarose no meio de cultura vem sendo citado como benéfico na melhoria da quali- dade do sistema radicular, bem como na sobrevivência das plântulas transplantadas (ANDRADE, 1998).

Aos 10 DAI, as médias da altura das brotações e do número de segmentos nodais por brotação responderam à variação da concentração de sacarose com máxima eficiência técnica estimada (MET) de 30 a $45 \mathrm{~g} \mathrm{~L}^{-1}$, e aos 25 e 32 DAI, entre 45 e $60 \mathrm{~g} \mathrm{~L}^{-1}$ (Figura 1b, c). Resultados semelhantes foram obtidos por RIBEIRO et al. (1998), que constataram maior crescimento para embriões de laranja "pêra" nas concentrações de sacarose entre 45 e $60 \mathrm{~g} \mathrm{~L}^{-1}$.

A média da altura de brotações e média do número de segmentos nodais por plântula foi maior aos 32 DAI do que aos 25 e 10 DAI, fato que indica o incremento crescente da biomassa das plântulas cultivadas in vitro. De acordo com NICOLOSO et al. (2003), comparando quatro concentrações de cinco fontes de carbono, a sacarose nas concentrações de 30,45 e $60 \mathrm{~g} \mathrm{~L}^{-1}$ foi a melhor fonte de carboidratos quanto ao número de brotações, altura de brotações, média da altura de brotações e número total de segmentos nodais por planta de $\boldsymbol{P}$. glomerata, portanto, demonstrando que esse carboidrato é o mais apropriado ao cultivo in vitro dessa espécie.

Com relação à matéria seca da parte aérea das plântulas de $\boldsymbol{P}$. glomerata cultivadas in vitro, aos 25 DAI, a MET à sacarose foi de $67,2 \mathrm{~g} \mathrm{~L}^{-1}$, sendo essa maior do que aquela obtida aos $32 \mathrm{DAI}$, a qual apresentou MET de 57,1 $\mathrm{g} \mathrm{L}^{-1}$ (Figura 1d). A matéria seca de raízes apresentou resposta cúbica com relação às concentrações de sacarose (Figura 1e) e a matéria seca total das plantas teve comportamento quadrático, com MET de 63,9g L-1 de sacarose (Figura 1f). Resultados semelhantes a esses foram obtidos por NICOLOSO et al. (2003), onde a elevação da concentração de sacarose de 30 até $60 \mathrm{~g} \mathrm{~L}^{-1}$ promoveu maior produção de biomassa dos órgãos de $\boldsymbol{P}$. glomerata cultivadas in vitro. $\mathrm{O}$ aumento da produção de biomassa da raiz para a cultura do morangueiro (Fragaria $x$ ananassa Duch) foi crescente até $45 \mathrm{~g} \mathrm{~L}^{-1}$ de sacarose (CALVETE, 1998). Já para a samambaiaespada (Nephrolepis exaltata L. Schott) propagada in vitro, o aumento de sacarose tendeu a apresentar os piores rendimentos (GUIMARÃES et al., 1999).

Os resultados obtidos para a $\boldsymbol{P}$. glomerata, considerando vários parâmetros de crescimento, indicam que concentrações acima de $60 \mathrm{~g} \mathrm{~L}$ ${ }^{1}$ de sacarose não são benéficas, seja pela elevada pressão osmótica do meio de cultivo (CALDAS et al., 1998) ou por um desbalanço nutricional qualquer (LEIFERT et al., 1995). Esses resultados também corroboram aqueles de GUIMARÃES et al. (1999), se- 


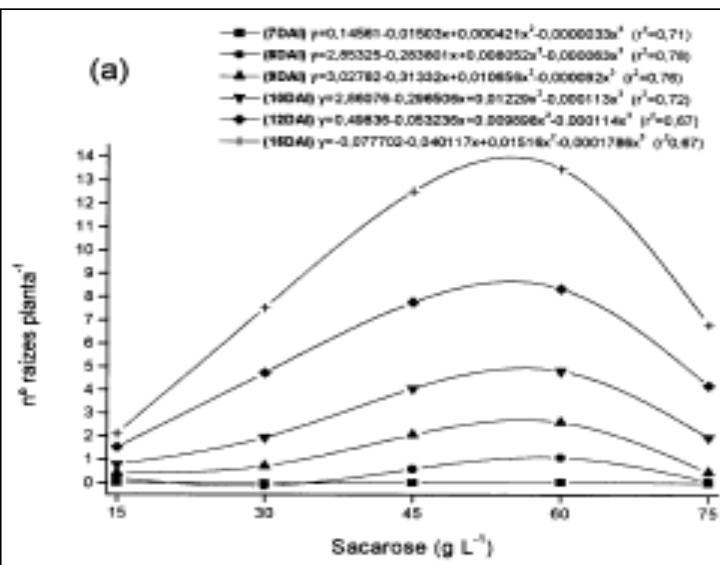

(c)

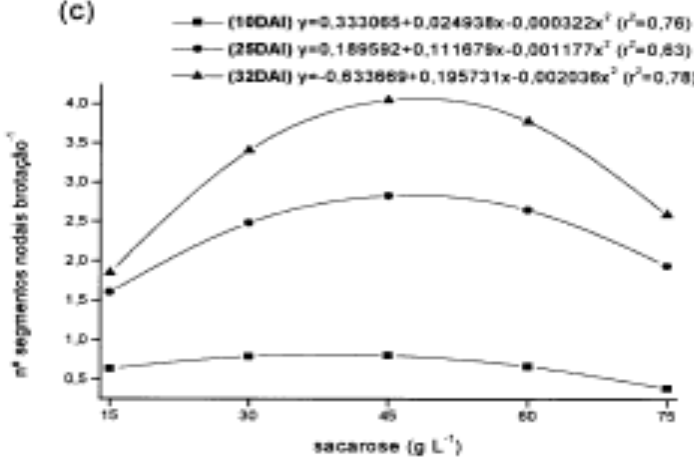

(e)

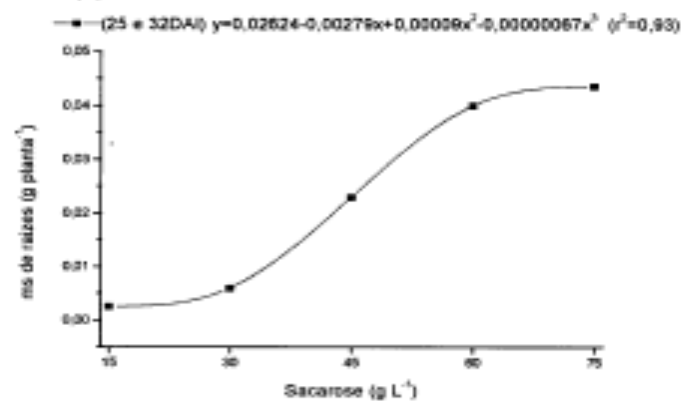

(b) $\quad-(100,0) y=0,009222+0,013524 x-0,000157 x^{2}\left(r^{2}=0,69\right)$ $\rightarrow-(25 D A 1) y=-2.965371+0.286975 x-0.00287 x^{2}\left(r^{2}-0.71\right)$

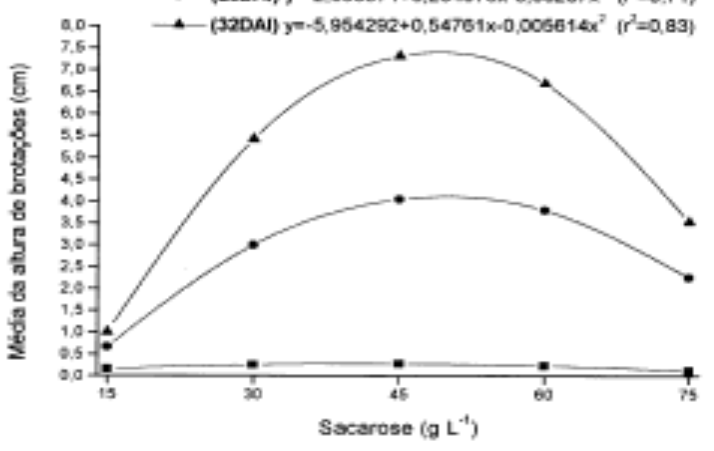

(d)

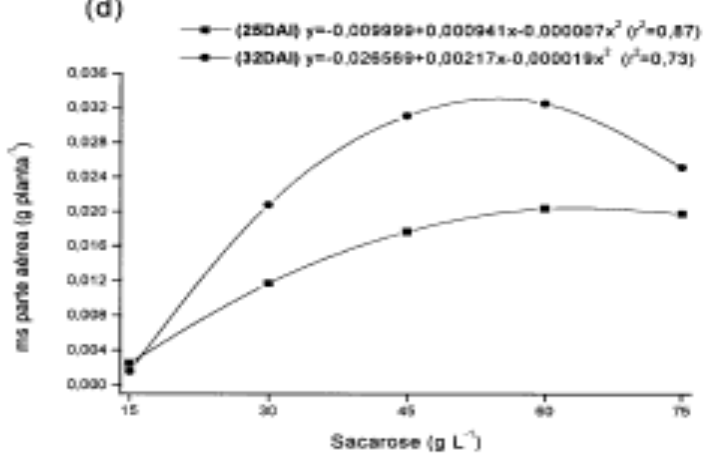

(f)

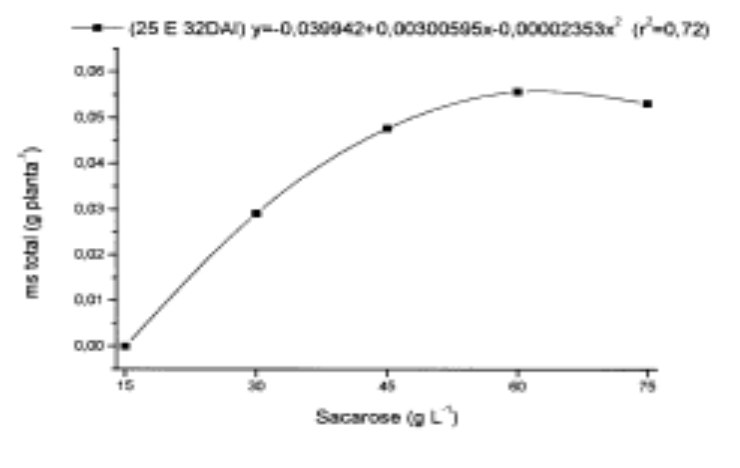

Figura 1 - Efeito de concentrações de sacarose no número de raízes (a), média da altura de brotações (b), média do número de segmentos nodais por brotação (c), matéria seca da parte aérea (d), de raízes (e) e total das plântulas (f) de Pfaffia glomerata cultivadas in vitro.

gundo os quais as otimizações do meio de cultura dependem da espécie estudada.

Aos 21 dias de cultivo ex vitro em câmara climatizada, houve efeito quadrático das concentrações de sacarose, com MET de $52,9 \mathrm{~g} \mathrm{~L}^{-1}$ para a matéria seca da parte aérea (Figura 2a) e $53,2 \mathrm{~g} \mathrm{~L}^{-1}$ para a matéria seca total (Figura 2c). A maior produção de matéria seca da parte aérea e total das plantas foi obti- da para as plantas retiradas aos 32 DAI. Com relação à matéria seca de raízes, as plantas retiradas do cultivo in vitro aos $25 \mathrm{DAI}$ apresentaram resposta linear positiva à sacarose. Já as plantas cultivadas até os 32 DAI apresentaram resposta quadrática com a maior produção de biomassa em $50,7 \mathrm{~g} \mathrm{~L}^{-1}$ de sacarose (Figura $2 \mathrm{~b}$ ).

A maior acumulação de biomassa da parte aérea e total das plantas oriundas do cultivo in vitro 


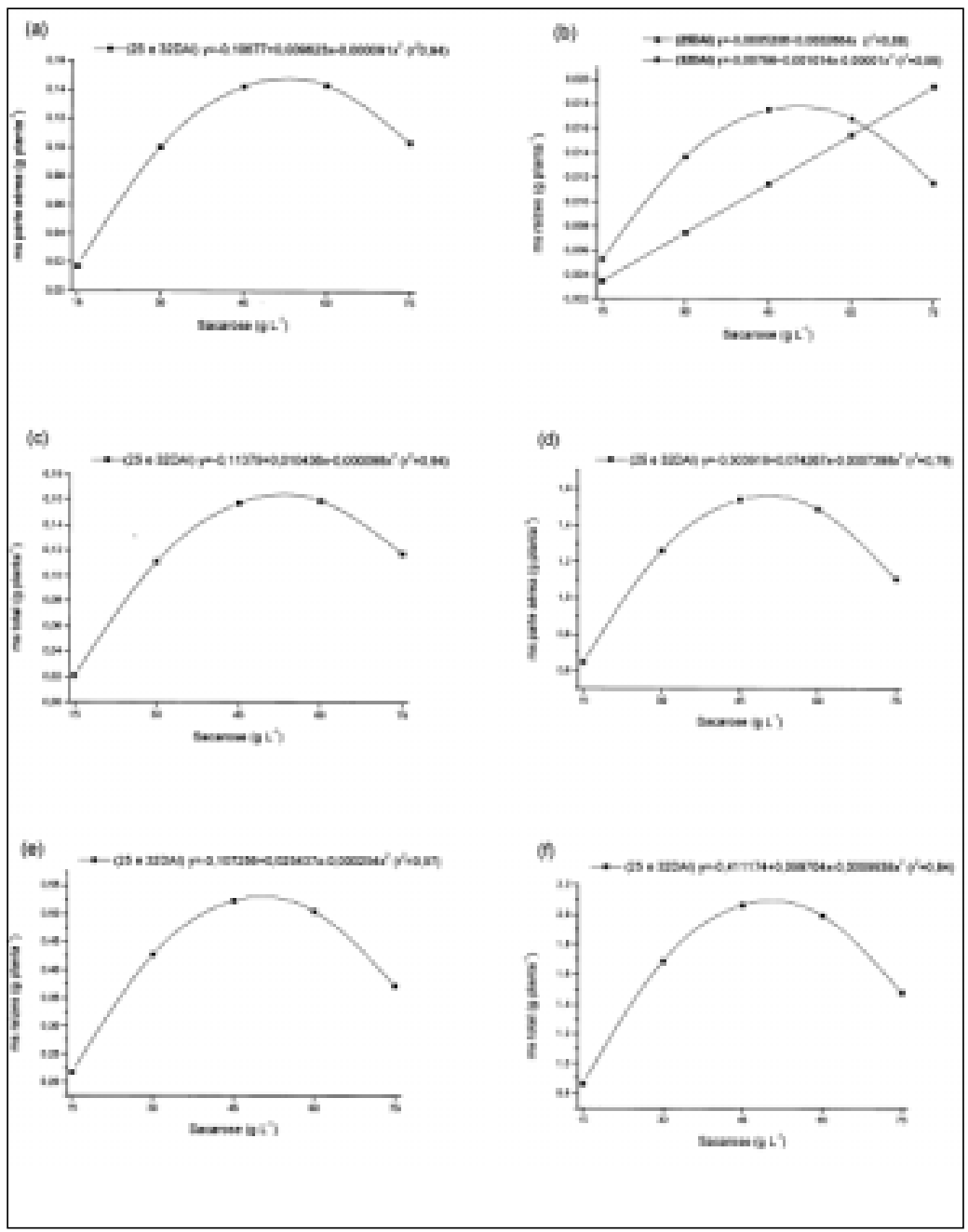

Figura 2 - Efeito de concentrações de sacarose e de épocas de retirada das plantas do cultivo in vitro sobre a produção de matéria seca da parte aérea (a), de raízes (b) e total das plantas (c) cultivadas em câmara climatizada por 21 dias, bem como na matéria seca da parte aérea (d), de raízes (e) e total das plantas (f) de Pfaffia glomerata cultivadas sob sombrite por 24 dias.

aos 32 DAI (Figura 2a, c), demonstra que o maior crescimento das plantas em função da permanência mais prolongada no sistema in vitro não prejudica a aclimatização ex vitro da $\boldsymbol{P}$. glomerata. Além disso, o benefício na produção de biomassa advindo do aumento da disponibilidade de sacarose, durante o cultivo in vitro, também não prejudicou a aclimatização.

Para os parâmetros de crescimento estudados, constata-se o efeito positivo da aclimatização $\boldsymbol{e x}$ vitro sobre as mudas $\boldsymbol{P}$. glomerata produzidas in vitro em diferentes concentrações de sacarose. Apesar das plantas oriundas do cultivo in vitro sob altas concentrações de sacarose, provavelmente, apresentarem menor taxa de fotossíntese (DALTON \& STREET, 1977;
SOLÍS et al., 1989; GRO et al., 1993), nota-se que, em função dos dados, essas plantas acumularam mais reservas de solutos, que podem ter sido utilizadas durante a aclimatização e, com isto, proporcionaram maior crescimento e desenvolvimento ex vitro. Estes dados corroboram aqueles relatados por CALVETE (1998) para o morangueiro.

Aos 24 dias de cultivo $\boldsymbol{e x}$ vitro sob sombrite, a matéria seca da parte aérea, de raízes e total das plantas respondeu à variação da concentração de sacarose com MET de $50 \mathrm{~g} \mathrm{~L}^{-1}$ (Figura 2d, e, f). Interessantemente, a diferença no crescimento entre as plantas retiradas aos 25 e 32 DAI até a $2^{\text {a }}$ fase de aclimatização, deixou de existir aos 24 dias de cultivo sob sombrite. Portanto, pode-se inferir que, após um certo período de cultivo ex vitro, que nesse caso coincidiu com o tempo de cultivo sob sombrite, as diferenças existentes pela maior produção de biomassa das plantas retiradas do cultivo in vitro aos 32 DAI, são sobrepujadas por outros fatores do ambiente que igualam o crescimento das plantas com diferentes idades de cultivo in vitro.

Quanto à porcentagem de sobrevivência das plantas cultivadas ex vitro, tanto aos 21 dias de cultivo em câmara climatizada (Figura 3a) como aos 24 dias de cultivo sob sombrite (Figura 3b), observou-se que aquelas retiradas do cultivo in vitro aos $25 \mathrm{DAI}$ na

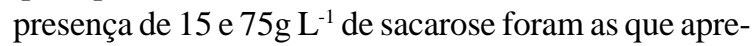
sentaram as menores percentagens de sobrevivência. Para as plantas desenvolvidas na presença de 30, 45 e $60 \mathrm{~g} \mathrm{~L}^{-1}$ de sacarose, não houve diferenças entre aquelas retiradas aos 25 e 32 DAI, as quais obtiveram $100 \%$ de sobrevivência.

A porcentagem de sobrevivência aos 30 dias sob cultivo a campo indicou que as plantas obtiveram excelente aclimatização, independe do período da retirada das plantas do cultivo in vitro, bem como da concentração de sacarose utilizada, exceto para aquelas oriundas de $15 \mathrm{~g} \mathrm{~L}^{-1}$ de sacarose que não obtiveram $100 \%$ de sobrevivência (Figura 3c). Para CALVETE 




Figura 3 - Efeito de concentrações de sacarose e de épocas de retirada das plantas do cultivo in vitro sobre a porcentagem de sobrevivência de plantas de Pfaffia glomerata aos 21 dias do cultivo em câmara climatizada (a), 24 dias em sombrite (b) e 30 dias a campo (c).

(1998), a maior taxa de sobrevivência do morangueiro, encontrada na presença de $45 \mathrm{~g} \mathrm{~L}^{-1}$ de sacarose, em relação às plantas oriundas da concentração de $15 \mathrm{~g} \mathrm{~L}^{-}$ ${ }^{1}$, pode ter ocorrido pelo acúmulo de sólidos nos tecidos, conferindo maior resistência às folhas, sugerindo que a presença de reservas de carbono nas folhas pode ser a principal forma de sustentar a sobrevivência das plantas, durante as primeiras semanas de aclimatização ex vitro.

O período total de aclimatização testado para as plantas de $\boldsymbol{P}$. glomerata, desde os três dias sem a presença do papel alumínio e filme plástico, mais os 21 dias de cultivo em câmara climatizada e os 24 dias sob sombrite, totalizou 7 semanas. De acordo com CALVETE (1998), considerando um período de 8 semanas de aclimatização para o morangueiro, as plantas necessitam de 3 a 4 semanas para se adaptarem às novas condições ambientais, e somente após retomam o crescimento. Desse modo, parece que a $\boldsymbol{P}$. glomerata apresenta comportamento semelhante ao morangueiro.

Os resultados obtidos neste trabalho indicam que a nutrição autotrófica, induzida in vitro, nem sempre conduz a um melhor crescimento das plantas quando comparado com aquele obtido em um meio de cultivo contendo sacarose. Alguns trabalhos mostram a influência positiva da sacarose no crescimento das plantas mesmo que se tenha enriquecido o ambiente com $\mathrm{CO}_{2}$. Em plântulas de fumo (Nicotiana tabacum L.), o crescimento foi ótimo quando as condições de enriquecimento de $\mathrm{CO}_{2}$ foram combinadas com o meio de cultivo contendo $20 \mathrm{~g} \mathrm{~L}^{-1}$ de sacarose (SOLAROVA et al., 1989). Em Dendrobium, LIM et al. (1992) também verificaram que o crescimento das plantas foi maior na presença de sacarose.

\section{CONCLUSÕES}

O maior crescimento de plantas de $\boldsymbol{P}$. glomerata é proporcionado pelas concentrações de 45 e $60 \mathrm{~g} \mathrm{~L}^{-1}$ de sacarose no cultivo in vitro. O período de retirada das plantas do cultivo in vitro não afetou a capacidade de aclimatização das plântulas.

\section{REFERÊNCIAS BIBLIOGRÁFICAS}

ANDRADE, L.B. Efeito do meio de cultura, tipos de explante e períodos de escuro sobre a micropropagação da batata (Solanum tuberosum L.), cv. Cristal. 1998. 60f. Dissertação (Mestrado em Agronomia) - Curso de Pós-graduação em Agronomia, Universidade Federal de Pelotas.

CALDAS, L.S.; HARIDASAN, P.; FERREIRA, M.E. Meios nutritivos. In: TORRES, A.C.; CALDAS, L.S.; BUSO, J.A. Cultura de tecidos e transformação genética de plantas. Brasília: Embrapa-SPI / Embrapa-CNPH, 1998. Parte II, p.87-132.

CALVETE, E.O. Concentração de sacarose in vitro e seleção de substratos para aclimatização ex vitro de morangueiro cv campinas (Fragaria ananassa Duch.). 1998. 108f. Tese (Doutorado em Fitotecnia) - Programa de Pós-graduação em Fitotecnia, Universidade Federal do Rio Grande do Sul.

CARVALHO, G.R. et al. Aclimatização de plantas de cafeeiro (Coffea arabica L.) propagadas "in vitro". Ciência e Agrotecnologia, Lavras, v.23, n.3, p.483-490, 1999.

DALTON, C.C.; STREET, H.E. The influence of applied carbohydrates on the growth and greening of cultured spinach (Spinacea oleracea L.) cells. Plant Science Letters, Amsterdam, v.10, p.157-164, 1977.

GEORGE, E.F. Plant propagation by tissue culture. Edington: Exegetics. 1996. Part 2, 1361p.

GRO, B. et al. The influence of sucrose and an elevated $\mathrm{CO}_{2}$ concentration of photosynthesis of photoautotrophic peanut (Arachis hypogea L.) cell 
cultures. Plant Cell, Tissue and Organ Culture, Hague, v.33, p.143-150, 1993.

GUIMARÃES, P.T.C.; PASQUAL, M.; MIRANDA, A.M.P.de. Efeito de diferentes concentrações de nitrogênio e de sacarose sobre a propagação "in vitro" da samambaia-espada [Nephrolepis exaltata (L.) Schott]. Ciência e Agrotecnologia, Lavras, v.23, n.2, p.309316,1999 .

LEIFERT, C. et al. Mineral and carbohydrate nutrition of plant cell and tissue cultures. Critical Reviews in Plant Sciences, Boca Raton, v.14, n.2, p.83-109, 1995

LEITE, G.B.; FINARDI, N.; FORTES, G.R.L. Efeitos de concentrações de sacarose no meio de cultura e da intensidade luminosa no enraizamento "in vitro" do porta-enxerto de pereira oh x f97. Ciência e Agrotecnologia, Lavras, v.24, n.2, p.353-357, abr/jun, 2000 .

LIM, L. et al. Effects of light intensity, sugar and $\mathrm{CO}_{2}$ concentrations on growth and mineral uptake of Dendrobium plantlets. Journal of Horticultiral Science, Kent, v.67, p.601$611,1992$.

MONTANARI JÚNIOR, I. Aspectos do cultivo comercial do ginseng brasileiro (Pfaffia glomerata (Spreng) Pedersen). Capturado em out. 2002. On line. Disponível na Internet: http:// www.cpqba.usp.br.

MURASHIGE, T.; SKOOG, F. A revised medium for rapid growth and bioassays with tobacco tissue cultures. Physiologia Plantarum, Copenhagen. v.15, p.473-497, 1962.
NICOLOSO, F.T.; FORTUNATO, R.P.; FOGAÇA, M.A. de F. Influência da posição da estaca no ramo sobre o enraizamento de Pfaffia glomerata (Spreng.) Pedersen em dois substratos. Ciência Rural, Santa Maria, v.29, n.2, p.277-283, 1999.

NICOLOSO, F.T.; CASSOL, L. F.; FORTUNATO,R.P. Comprimento da estaca de ramo no enraizamento de ginseng brasileiro (Pfaffia glomerata). Ciência Rural, Santa Maria, v.31, n.1, p.57-60, 2001a.

NICOLOSO, F.T. et al. Micropropagação do ginseng brasileiro. [Pfaffia glomerata (Spreng.) Pedersen]. Revista Brasileira de Plantas Medicinais, Botucatu, v.3, n.2, p. 11-18, $2001 \mathrm{~b}$.

NICOLOSO, F.T. et al. Efeito de concentrações e fontes de carboidratos no crescimento de plantas de ginseng brasileiro (Pfaffia glomerata (Spreng.) Pedersen) cultivadas in vitro. Ciência e Agrotecnologia, Lavras, v.27, n.1, p.84-90, 2003.

RIBEIRO, V.G. et al. Cultivo in vitro de embriões de laranja "pêra": concentrações do meio MS e sacarose. Ciência e Agrotecnologia, Lavras, v.22, n.4, p.429-434,1998.

SMITH, L.B.; DOWNS, R.J. Flora ilustrada catarinense. v. Amarantáceas. Itajaí: Herbário Barbosa Rodrigues, 1972. 110p.

SOLAROVA, J. et al. Photosynthesis and growth of tobacco plants in dependence on carbon supply. Photosynthetica, Dordrecht, v.23, p.629-637, 1989 .

SOLÍS, C. et al. The biogenesis of chloroplasts in tissue cultures of a C3 and C4 plant. Plant and Cell Physiology, Kyoto, v.30, p.609616, 1989. 